Educa-UMCH, 15, enero - junio 2020 https://doi.org/ 10.35756/educaumch.202015.132 ISSN: 2617-0337

\title{
La mística del servicio y el compromiso ético como fundamento de la responsabilidad social de la UMCH
}

The mystique of service and ethical commitment as the foundation of UMCH's social responsibility.

Recibido: 27 de noviembre 2019, Evaluado: 28 de febrero 2020, Aceptado: 01 de junio 2020

\section{Mónica Aguirre Garayar} maguirre@umch.edu.pe

https://orcid.org/0000-0003-3668-4451

Docente de la Universidad Marcelino Champagnat

\section{Como citar el artículo}

Aguirre Garayar, M. (2020). La mística del servicio y el compromiso ético como fundamento de la responsabilidad social de la UMCH. Revista EDUCA UMCH, (15), 36-47. https://doi.org/10.35756/educaumch.202015.132

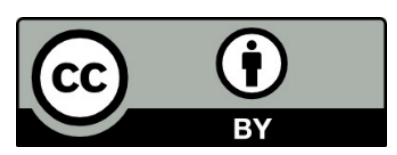

Esta obra está bajo una licencia internacional Creative Commons Atribución 4.0. 
Yo puedo hacer cosas que tú no puedes, tú puedes hacer cosas que yo no puedo;juntos podemos hacer grandes cosas. Madre Teresa de Calcuta

\section{Resumen}

El artículo es fruto de una ponencia como parte de una mesa redonda denominada: "Responsabilidad en la Universidad", organizada por el II Seminario Internacional cuyo lema fue "Impacto de la investigación científica en la sociedad". Tiene como objetivo generar una reflexión crítica sobre los fundamentos de la RSU, ya que para hablar del impacto de una acciónes conveniente reflexionar en aquello que la origina, fundamenta o desencadena. Contempla larevisión del estado del arte sobre el tema en publicaciones arbitradas; cuestiona diversos planteamientos generados en torno al tema en el medio académico y educativo. Propone, comocentro de la RSU el valor de la persona humana de la cual deviene la mística del servicio y el compromiso ético; valores que propugna esta Universidad y, finalmente, comparte la experiencia de responsabilidad social que tiene esta Casa de Estudios, desde su creación, comoconsecuencia de un compromiso ético que promueve el desarrollo humano y sostenible.

Palabras clave: Responsabilidad social, desarrollo humano, primacía de la persona, mística del servicio, compromiso ético.

\section{Abstract}

The article is the result of a presentation as part of a round table called: "Responsibility at theUniversity", organized by the II International Seminar whose motto was "Impact of scientificresearch on society". Its objective is to generate a critical reflection on the fundamentals of theRSU, since in order to speak of the impact of an action it is convenient to reflect on whatoriginates supports or triggers it. It contemplates the revision of the state of the art on the subjectin refereed publications; questions various approaches generated around the subject in theacademic and educational environment. It proposes, as the center of the RSU, the value of thehuman person from which the mystique of service and ethical commitment becomes; values espoused by this University and, finally, it shares the experience of social responsibility that this House of Studies has, since its creation, as a consequence of an ethical commitment that promotes human and sustainable development.

Keywords: Social responsibility, human development, primacy of the person, mystique of service, ethical commitment. 


\section{Planteamiento inicial}

Todos, probablemente, coincidamos con la siguiente premisa: "La educación superior tiene la responsabilidad social de ayudar en la comprensión de problemas sociales, económicos, científicos y culturales, así como en la capacidad de hacerles frente" (UNESCO, 2009: 2). Al mismo tiempo, seguramente, un buen grupo, está convencido de que una buena universidad, como afirma Goergen (2007):

no es la que contribuye a la mejora del rendimiento del sistema, sin preguntar lo que ello significa, sino que pone sus habilidades al servicio de la sociedad y de su humanización; esto es, comprender el mundo y no meramente manipularlo, reubicandoa la persona, al sujeto, en el centro del proceso del conocimiento, de la relación con la naturaleza y de los hombres entre sí.

Por ello, es importante cuestionarnos sobre qué entendemos por RSU y sobre las bases sobre las cuales se funda esta responsabilidad, dado que, hoy en día, pareciera que este término, al contrario de lo que se espera, estaría perdiendo sentido.

\section{Qué entendemos por RSU}

Rescato el siguiente concepto de responsabilidad social universitaria con el cual me identifico:

Proceso dinámico de acciones compartidas (corresponsabilidad) entre organizaciones públicas y comunidad en general. Se trata de acciones conjuntasnecesarias para generar los cambios que se requieren para la integración sector universitario y la comunidad, para lo cual hay que estar consciente del bienestarque se proporcionará a la sociedad. Es un proceso medular básico de acción quetoma en cuenta las expectativas de la gente y promueve el compromiso social; todo ello, con la intención de lograr la integración organizacional con las comunidades locales (Crasto, Marín y Senior, 2016).

Domínguez Granda y Rama, en esa misma línea afirman que:

.. la Responsabilidad Social Universitaria entraña a la misma naturaleza y misión de la Universidad y no es algo temporal o pasajero que respondesimplemente a una tendencia moderna, sino que asume compromisos de solidaridad, justicia y desarrollo responsable. Además, exige que la comunidad universitaria ponga en práctica aquello que figura en su misión o planes estratégicos. (Domínguez y Rama, 2016).

En efecto, concebimos que la responsabilidad social en la universidad es inherente a su misma naturaleza, y, en definitiva, es la respuesta ética consistente con sus principios. Si tuviéramos que preguntarnos si la RSU es un fin o un medio (Rodríguez, 2006), no compartiríamos algunas posturas que la proponen como uno de los fines de la universidad; 
tampoco con quienes la

proponen como el fundamento para una gestión socialmente responsable (Valdés y Villegas, 2017), o como una nueva filosofía de gestión universitaria que pretende renovar el compromiso social de la Universidad (Vallaeys, 2007). La misma Ley universitaria, en el artículo $124^{\circ}$ la define como la gestión del impacto generado en la sociedad debido al ejercicio de sus funciones; y la califica como ética y eficaz (Ley 30220, 2014)

Nosotros, consideramos, más bien, a la responsabilidad social de la Universidad como fruto de una gestión basada en la ética y en la eficiencia, que supera la mera filantropía y la gestión organizacional. (Domínguez y Rama, 2016), siendo esta gestión, consecuencia de una visión que se orienta por principios, convicciones y fines. En pocas palabras, conceptualizamos la RSU, como un resultado y no como el origen.

\section{Fundamentos de la RSU en la UMCH}

\section{a. La primacía de la persona}

Al entender a la RSU como una consecuencia, como un resultado, como una acción que brota de un postulado, de un principio o fundamento, entendemos que ese principio no es otro que la persona humana y el respeto de su dignidad ( $\mathrm{Art}^{\circ} 1$ Constitución Política del Perú, 1993), definiendo a la persona humana como el ser de naturaleza racional, digno, libre y social: situado en la historia, en la cultura y en el mundo; portador de potencialidades que se desarrollan a través de la vida mediante la solidaridad con los demás; como aquel sujeto moral que tiene un yo consciente, unitario, que se descubre un ser en relación con y para los demás; abierto a la trascendencia y a lo espiritual.

A partir de esta concepción, afirmamos que es esta persona que se constituye como el centro de la responsabilidad social (De la Guerra de Urioste, 2015).

En ese sentido, la Universidad M. Champagnat propugna 7 valores institucionales, siendo el primero, el de la Primacía de la persona, que declara que "encuentra en la persona humana el sentido de su ser y quehacer. Reconoce el valor de todos los miembros de su institución y procura su desarrollo..." (Valores UMCH, 2013).

Ahora bien, si atendemos al artículo $6^{\circ}$ de la Ley universitaria, que al hablarnos de los fines de la Universidad, no menciona a la RSU como uno de sus fines; más bien, atendiendo a una tradición humanística, presente en la Ley, plantea como fines, entre otros, el de formar profesionales de alta calidad y con pleno sentido de responsabilidad social; proyectar a la comunidad sus acciones y servicios para promover su cambio y desarrollo; colaborar de modo eficaz en la inclusión social; afirmar y transmitir las diversas identidades culturales del país; promover el desarrollo humano y sostenible; servir a la comunidad y al desarrollo integral y formar personas libres en una sociedad libre. (Ley 30220, 2014). De esta declaración, deviene la ineludible responsabilidad de formar personas libres, con sentido de responsabilidad social; promover el desarrollo humano con respeto a la diversidad cultural, favoreciendo la igualdad de oportunidades 
y, que dicho desarrollo sea sostenible.

La imperante responsabilidad de promover el desarrollo humano y sostenible se ve reflejada en nuestra misión de propugna: Formar personas, profesionalmente competentes, comprometidas con la sociedad y con una visión humanístico-cristiana, inspirados en el carisma marista. (Plan estratégico UMCH 2018-2021).

Alineada a esta misión, la Universidad cuenta con una política en la que asume y promueve entre sus miembros la responsabilidad social, como un rasgo peculiar.

- Promueve el cultivo de valores sociales e individuales, como son el de ciudadanía y responsabilidad social, desarrollo sostenible y educación inclusiva y abierta a la diversidad, a través de su proyecto formativo.

- Motiva en todos los integrantes de la comunidad universitaria la práctica ética en el ejercicio de sus funciones.

- Promueve proyectos con impacto social, de manera prioritaria entre los más pobres.

- Forma profesionales de calidad con equidad e inclusión.

- Desarrolla una mística del trabajo, del servicio y del compromiso con los otros en acciones de extensión universitaria, de proyección social y/o pastoral inscritas en el currículo. (Política de responsabilidad social, UMCH, 2016)

\section{b. EI horizonte ético}

En una sociedad postmoderna que ha desechado los valores universales, que se alimenta del escepticismo, del culto a la apariencia y de un desencanto sobre la supuesta omnipotencia de la razón (Ruiz Román, 2010), que se nutre de la fugacidad de lo provisional: Todo lo que hoy es, alguna vez no ha sido y probablemente en el futuro no será. No existen cosas permanentes, puntos invariables (Fontán, 1996); el ser humano, en búsqueda de sentido, necesita fundamentar su vida y su acción en un proyecto de vida valioso.

Otro valor que esta Casa de estudios propone como fundamento del ser y quehacer institucional UMCH, es el Horizonte Ético, que es consciente que el proyecto formativo que brinda, tiene como punto de partida y horizonte, una respuesta ética de cada uno de los miembros de su comunidad.

Promueve el cultivo de valores sociales e individuales: la verdad, el bien y la belleza; la honestidad y la sencillez en el actuar; la búsqueda del bien común sobre los intereses individuales; el fomento de la solidaridad; el respeto de las personas, de sus ideas y creencias, y la defensa de los derechos humanos. (ValoresUMCH,2013) 
"Como sujetos morales asumimos la responsabilidad social como este imperativo categórico que nos motiva a obrar de tal modo que uses la humanidad, tanto en tu persona como en la persona de cualquier otro, siempre como un fin al mismo tiempo y nunca solamente como un medio" (Kant, 1995: 44-45).

\section{c. La mística del servicio}

Más aún, ante esta fragmentación de lo moral, de un mundo desmitificado, donde los valores últimos y más sublimes han desaparecido de la vida pública y se han retirado, o bien al reino de la vida mística, o bien a la fraternidad de las relaciones inmediatas de los individuos entre sí (Weber, 1998), se hace indispensable remitirnos a un rasgo del ser humano que nos puede rescatar del individualismo narcisista: la alteridad. "El rostro del otro es doblemente saludable en la medida que libera al yo de sí mismo y en la medida en que lo desembriaga de su complacencia y de su soberbia" (Finkielkraut, 1999, p. 25).

Como refiere, Ruiz (2010) es importante propiciar la experiencia del "otro"; ser capaces, como sujetos o como comunidad, de fomentar actitudes de acercamiento y corresponsabilidad con el "otro", instalando una cultura de colaboración, de generosidad y de desprendimiento personal. Es por ello, que promovemos, como rasgo peculiar, otro de nuestros valores al que denominamos mística del servicio, que fundamenta la identidad y el accionar personal e institucional; mística, entendida como compromiso total, al servicio de algo a de alguien.

Cultiva la mística del trabajo, del servicio y del compromiso con los otros y se esfuerza por brindar una formación de calidad con equidad e inclusión. Propendeun "saber" mayor que conduzca a un "ser" mejor, para poder "servir" más y mejor. Cada integrante de la comunidad se constituye así en hombre o mujer "para los demás" y "con los demás". (Valores UMCH,2013)

De ahí que la responsabilidad social universitaria en la UMCH se fundamenta en un horizonte ético y en una mística del servicio que tiene como principio la primacía de la persona y que trasciende el ámbito académico y de investigación para concretarse en acciones de promoción humana, de solidaridad, de apertura al diálogo, de una comprensión y una tolerancia a la pluralidad, respetando las diferencias.

\section{La gestión de la RSU en la UMCH}

Para sintetizar las acciones de responsabilidad social que ejerce la Universidad, me he permitido organizarlas en cuatro ejes de gestión, que son consecuentes con la finalidad última que es promover el desarrollo humano y sostenible. 


\section{Figura 1}

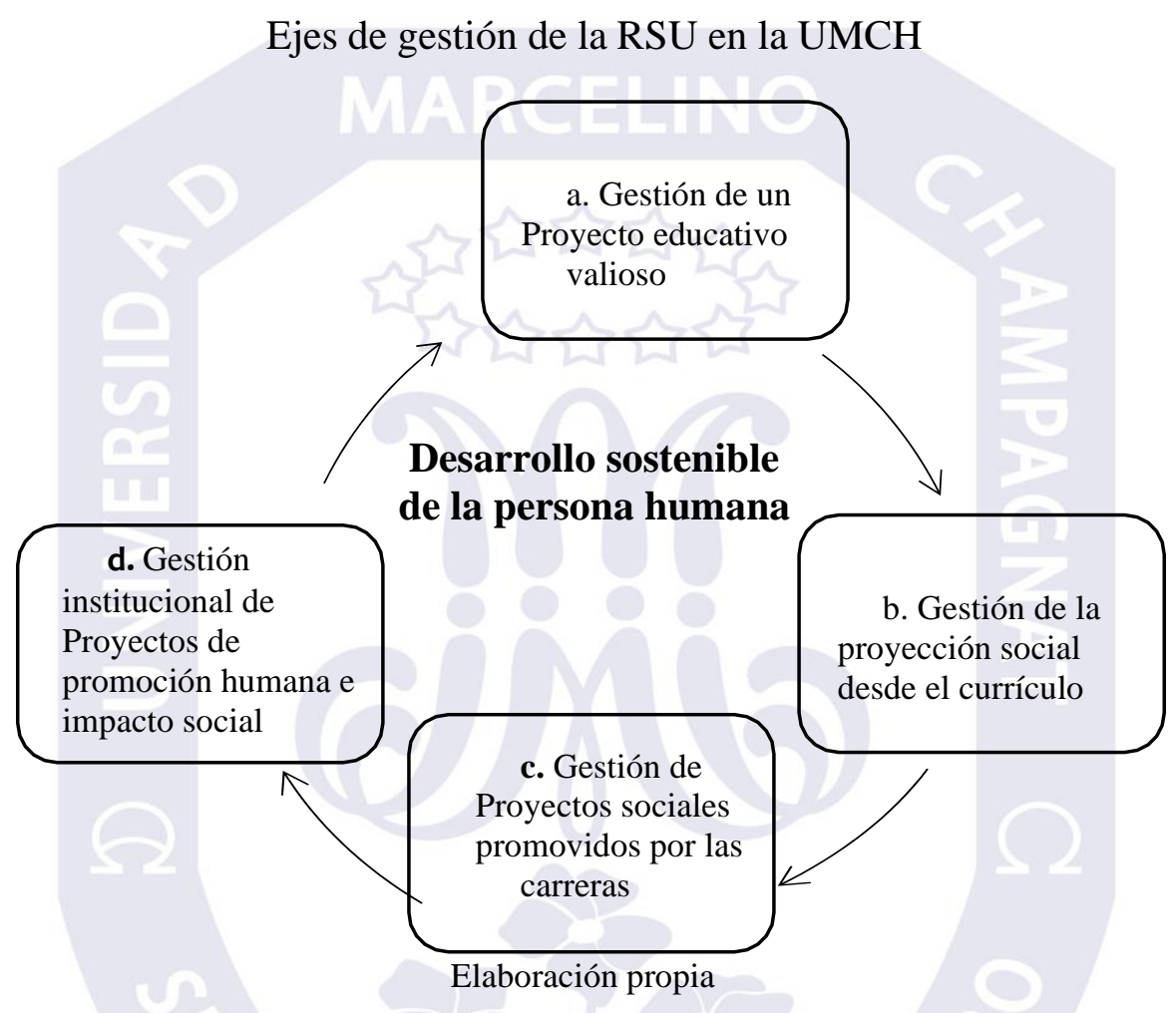

\section{a. Gestión de un proyecto educativo valioso}

La Universidad trata de fomentar entre todos los integrantes de la comunidad universitaria la vivencia de valores universales y cristianos, respetando las diversas confesiones religiosas. Orienta su servicio a partir de un modelo educativo propio y de un planeamientoestratégico a largo plazo. Pero, más importante aún, fomenta una cultura y un clima fraternodonde cada persona es importante.

\section{b. Gestión de la proyección social desde el currículo}

Si bien entre los años 1990 y 2005, los estudiantes realizaban diversas actividades de proyección social durante los cinco años de carrera, es desde el año 2006 que se incluyeronen todos los planes de estudios actividades de proyección social, con horas de trabajo de campo, creditaje y nota. Añadido a ello, desde el año 2010, se cuenta con el Centro de Extensión Cultural y de Proyección Social (CEPS), que lidera 4 proyectos sociales anualescon la participación de estudiantes y docentes. A lo largo de los años, se ha colaborado estrechamente con albergues, casas hogares, centros de rehabilitación, cunas, asentamientos humanos, a través de proyectos organizados por la UMCH. También se han gestionado diversos convenios con otras instituciones fomentando el voluntariado de nuestros estudiantes. El porcentaje promedio de participación de nuestros estudiantes es del $85 \%$ y, el número de beneficiarios promedio por año, los últimos siete años, asciende a 395 personas. 
Por otro lado, desde el 2006 hasta la actualidad, se ha incluido, en las mallas curriculares, asignaturas de responsabilidad social, de desarrollo sostenible, de inclusión y discapacidad.

\section{c. Gestión de proyectos sociales por carreras}

Aunque la Universidad viene impulsando los proyectos de innovación pedagógica y de promoción social desde su creación, primero desde la Oficina de Práctica Profesional, luego, desde la Pastoral Universitaria, y, finalmente, desde el CEPS; es, desde el año 2012, que se ha comenzado a promover en cada carrera la elaboración, ejecución y evaluación de cada proyecto social que, a partir de una problemática, genere una respuesta o ayude a generar un cambio. Dichos proyectos, monitoreados desde el CEPS, involucran a las Escuelas profesionales, a docentes, estudiantes y personal administrativo, que ejercita esta mística del servicio. El promedio anual de personas beneficiadas a través de estas actividades es de 966 personas.

\section{Figura 2}

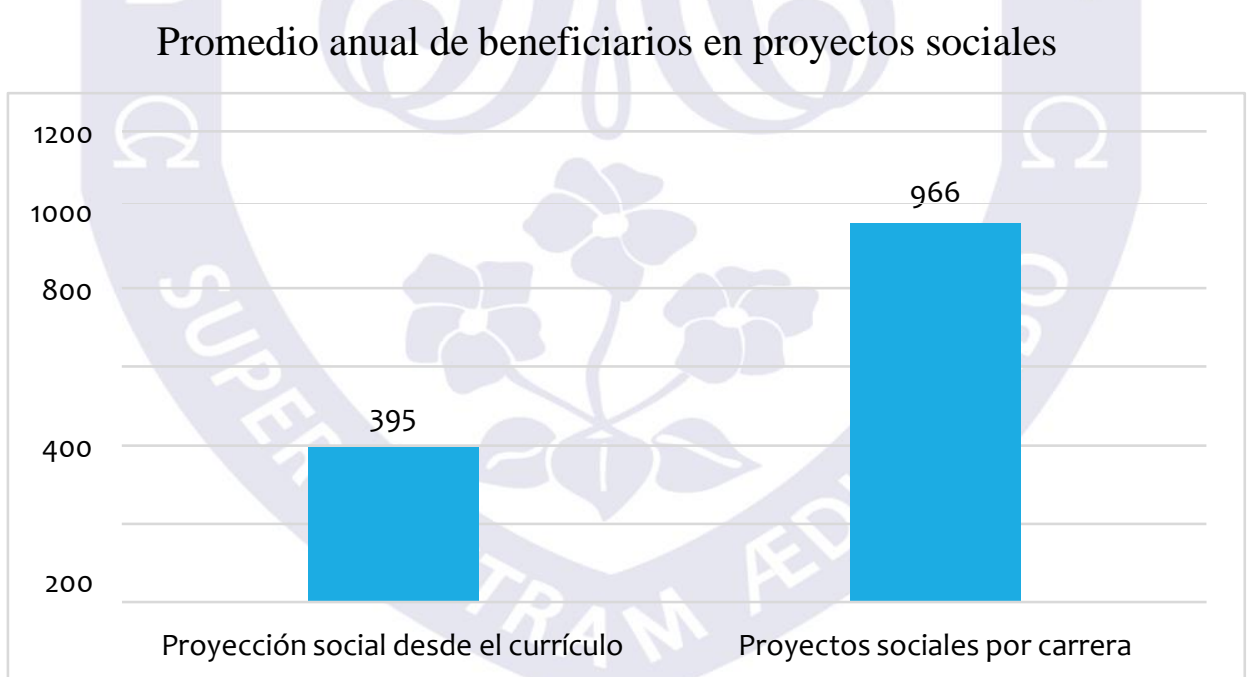

Elaboración propia con data de los informes de resultados CEPS 2013 a 2018.

\section{d. Gestión institucional de proyectos de promoción humana e impacto social}

Desde sus inicios, la UMCH ha buscado responder a las necesidades emergentes desde el campo educativo. Por ello, crea en el año 1992 la Modalidad Semipresencial, a fin de profesionalizar a docentes de todo el país. A partir de enero de 1993, en colaboración con la propia Congregación Marista, apoyó la organización y ejecución de un Programa de Profesionalización docente de maestros no titulados de Educación Primaria de la zona de San Lorenzo de Yurimaguas en la Amazonía Peruana. La colaboración de las diversas instituciones implicadas en el proyecto posibilitó que los estudios estuviesen exentos de cualquier costo para los estudiantes. (González, 2003) El número de docentes beneficiadoscon el proyecto sobreasó el 
medio millar de personas y el tiempo de duración fue aproximadamente de 7 años.

Esta experiencia se ha seguido replicando, aunque, al pasar de los años, las propuestas y losdestinatarios han ido cambiando.

El proyecto "Un maestro para el Datem" constituye uno de los proyectos de promoción humana e impacto social más queridos que lleva adelante esta Casa de estudios a favor de los pueblos de la Amazonía. El objetivo fundamental es titular a unos 500 docentes nativosbilinguies. El mismo rector impulsa dicho proyecto:

En efecto, a finales del año 2011, la Universidad acogió la petición de los pueblos originarios quienes a través de sus "apus" o jefes carismáticos solicitaban que nos comprometiésemos en la formación de los actuales y futuros maestros de sus escuelas. Desde esa fecha, se han ido congregando algo más demedio millar de jóvenes y adultos de los ocho pueblos originarios que viven enel Datem: achuar, awajún, chapra, kandozi, kichwa amazónico, shawi, shiwilo ywampis. Un pequeño grupo de mestizos residentes en la zona completa el cuadro de estudiantes. (González, 2019)

Con el mismo entusiasmo, la Universidad desde el año 2017 contribuye con el Programa Nacional de Formación y Capacitación de Directores y Subdirectores de Instituciones Educativas, en convenio con Minedu, formando durante los años 20162017 a más de 2,400 docentes y, en el año 2019 a 2, 760 directores a nivel nacional.

Gestiona, a la vez, alianzas estratégicas con algunas instituciones con las cuales desarrolla proyectos de impacto social, como, es el caso de la implementación, a nivel nacional, del Proyecto Comunidades de Aprendizaje, con presencia en 15 regiones del país, financiado por la Empresa Natura Cosméticos y operado por $\mathrm{UMCH}$.

\section{Tabla 1}

Beneficiarios en proyectos de desarrollo e impacto social, 2017-2018-2019

Proyectos de desarrollo e impacto social

\begin{tabular}{lc}
\hline Proyecto “Un Maestro para el Datem” & 500 \\
Proyecto de especialización de directores y sub & 516 \\
directores & 0 \\
Proyecto de Comunidades de aprendizaje & 32,000 \\
\hline
\end{tabular}

Total

Elaboración propia

\section{beneficiarios}

$37,660.00$

\section{$37,660.00$}




\section{Conclusiones}

La responsabilidad social universitaria promueve "tomar partido por el otro"; involucrarse en el desarrollo local, regional y nacional; crea las condiciones para aprender a mirar, a escuchar, a sentir con el otro; fortalecer una conciencia ética frente al destino común. En consecuencia, el rol que como Universidad nos toca asumir es la defensa de la persona humana, el respeto porel otro, la educación en una ciudadanía activa y solidaria que nos obliga a ir más allá de nosotrosmismos y que nos invita a preocuparnos por otras personas. Este es el imperativo ético que como institución de educación superior no podemos eludir.

\section{Referencias}

Bauman, Z. (2004). Ética postmoderna. Buenos Aires: Siglo XXI.

Bauman, Z. (2007). Los retos de la educación en la modernidad líquida. Barcelona: Gedisa. Cortina, A. (1986), Ética Mínima, Madrid: Tecnos, 2004 (9aed.).

Crasto, C., Marín, F., \& Senior, A. (2016). Responsabilidad social en la gestión universitaria:una construcción colectiva. Espacio Abierto, 25(2), 185-208.

Díaz de la Cruz, C., \& Fernández, J. L. (2016). Marco conceptual de la ética y la responsabilidadsocial empresarial: un enfoque antropológico y estratégico. Revista Empresa y Humanismo, Vol. XIX n ${ }^{\circ}$ 2, 69-118. Madrid: Universidad Pontificia Comillas.

Domínguez, J., \& Rama, C. (2016). La responsabilidad social universitaria en la educación adistancia. Chimbote: Uladech

Enciso-Congote, J. D. (2017). Implicaciones éticas que se desprenden de algunas corrientes deresponsabilidad social: los bienes, las normas y las virtudes. Revista Empresa y Humanismo.20 (2), 2017, 7 - 28. Navarra: Universidad de Navarra

Finkielkraut, A. (1987). La derrota del pensamiento. Barcelona: Anagrama. Finkielkraut, A. (1999). La sabiduría del amor. Barcelona: Gedisa

Fontán, M. (1996). Arraigos personales portátiles o formación de la subjetividad. Educar en la época tecnoartística del mundo en García Hoz, V (dir.) Enseñanzas artísticas y técnicas. (Tratado de educación personalizada). Vol.18. Madrid. Rialp.

González, K. V., \& López, J. M. T. (2014). Responsabilidad Social Universitaria. Apuntes paraun modelo de RSU. Revista de comunicación (13), 84-117. Loja: Universidad Técnica particular de Loja. 
González, P. (2019) Artículo: Del corazón de Champagnat al corazón del Datem recuperado de https://www.champagnat.org/400.php? $\mathrm{a}=6 \& \mathrm{k}=5316$

González, P. (2003) Tesis Doctoral "Universidad Marcelino Champagnat” (19901995): Continuidad y ruptura. Lima: UMCH.

Kant, I. (1995), Fundamentación de la metafísica de las costumbres. Crítica de la razón práctica. México: La paz perpetua, Porrúa.

Laurencio, A., \& Farfán, P. C. (2016). La innovación educativa en el ámbito de la responsabilidad social universitaria. Revista Cubana de Educación Superior 35(2), 16-34. Recuperado en 14 de marzo de 2020, de http://scielo.sld.cu/scielo.php?script=sci_arttext\&pid=S025743142016000200002 \&lng=es\&tlng=es.

López, A.(2012). Karol Wojtyla y su visión personalista del hombre. Cuestiones Teologicas, vol. 39, no. 91, p. 119-137, june 2012. ISSN 2389-9980. Available at: https://revistas.upb.edu.co/index.php/cuestiones/article/view/1148. Date accessed: 30 Oct. 2019.

Magendzo, A. (2006) El Ser del Otro: un sustento ético-político para la educación, Polis [En línea], 15 | 2006, Publicado el 04 agosto 2012, consultado el 01 noviembre 2019. URL: http://journals.openedition.org/polis/4897

Martin, J. (2009), El fenómeno místico. Estudio comparado, Trotta, Madrid.

Martínez-Usarralde, M. J., Lloret-Catalá, C., \& Mas-Gil, S. (2017). Responsabilidad Social

Universitaria (RSU): Principios para una universidad sostenible, cooperativa y democrática desde el diagnóstico participativo de su alumnado. Archivos Analíticos dePolíticas Educativas, 25(75). http://epaa.asu.edu/ojs/article/view/2769

Melloni, J. (2011), Hacia un tiempo de síntesis. Barcelona: Fragmenta.

Merton, Thomas (2004), La experiencia interior. El encuentro del cristianismo con el budismo. Paidós: Barcelona.

Morataya, J. La experiencia educativa solidaria: recurso fundante de la Responsabilidad SocialUniversitaria (2010). Revista Cultura de Guatemala, ${ }^{\circ}$ 31, Volumen 1, 2010. 105 -108.

Mounier, E. (1974) El Personalismo. Editorial Universitaria de Buenos Aires, Buenos Aires. 
Noguera, J. J. M., Martí-Vilar, M., \& Almerich, G. (2014). Responsabilidad social universitaria: influencia de valores y empatía en la autoatribución de comportamientos socialmente responsables. Revista Latinoamericana de Psicología, 46(3), 160-168. http://roderic.uv.es/handle/10550/41371

Noguera, M., José, J., Pérez Morán, G., Lara, C., \& Dyann, E. (2019). Legislación de la responsabilidad social universitaria: Estudio de casos en universidades de Perú y Ecuador. Revista Venezolana de Gerencia (RVG). Maracaibo: Universidad del Zulia.

https://www.researchgate.net/publication/330384373Legislaciondelaresponsabili dadsocialuniversitariaEstudiodecasosenuniversidades_de_Peru_y_Ecuador

Rodríguez Fernández, J. M. (2006). La responsabilidad social de la empresa: ¿un medio o un fin? Revista de Dirección y Administración de Empresas, 13, 53-77. Calladolid: Universidad de Valladolid. https://www.ehu.eus/ojs/index.php/rdae/article/viewFile/11457/10593

Rueda López, R. (2017). La ética como fundamento de la responsabilidad social: la perspectivade género como praxis socialmente responsable en la universidad. Córdova: UCOpress.

Ruiz Román, C. (2010). La Educación en la sociedad postmoderna: Desafíos y oportunidades.Revista Complutense De Educación, 21(1), 173 - 188. Recuperado a partir de https://revistas.ucm.es/index.php/RCED/article/view/16093

Stassi, H. M., \& Hoffmann, G. E. (2019). Aportes de la Responsabilidad Social Universitaria (RSU) a la generación de valores éticos sociales. Córdoba: Universidad Siglo 21.

Vallaeys, F. (2008) Responsabilidad Social Universitaria: una nueva filosofía de gestión éticae inteligente para las universidades. Educación superior y sociedad, 13(2), 191-220.

Weber, Max (1998) El político y el científico. Alianza: Madrid.

Yúfera, J. Mística y ética: desafíos para nuestro tiempo. De la experiencia mística a la acción moral. Isegoría, [S.1.], n. 53, p. 679-695, dec. 2015. ISSN 1988-8376. Disponible en: http://isegoria.revistas.csic.es/index.php/isegoria/article/view/920 Fecha de acceso: 31 oct. 2019.

Zuluaga, D. A. B. (2014). El concepto de persona humana en la tradición cristiana y su progresión hasta el personalismo. Cuestiones Teológicas, 41(96), 467-493. Medellín: Universidad pontificia Bolivariana. http://www.scielo.org.co/pdf/cteo/v41n96/v41n96a10.pdf 